\title{
Prosecution and Diversion within Criminal Justice Systems in Europe. Aims and Design of a Comparative Study
}

\author{
Jörg-Martin Jehle • Marianne Wade • Beatrix Elsner
}

Published online: 29 July 2008

(C) Springer Science + Business Media B.V. 2008

\begin{abstract}
This article presents the aims, approach and design of a 11 countries study on diversion and prosecution in European Criminal Justice Systems. The basic assumption is that the flood of proceedings is mastered by procedural short cuts and simplifications with the public prosecutor as the key player. The article describes the methods developed in order to compare the different national concepts and and competencies of criminal justice agencies and procedures. Furthermore, it demonstrates the interdependencies of the various articles in this double issue focusing on different parts of the criminal justice system from police to the court.
\end{abstract}

Keywords Comparative study · Criminal justice systems · Discretion · Diversion · Methodology $\cdot$ Prosecution

\section{Outline of the Study}

This comparative study presented in this volume is an expanded follow-up of the 6-country study into the "Function of the Prosecution Services in Criminal Justice Systems" documented in Jehle/Wade "Coping with Overloaded Criminal Justice Systems". ${ }^{1}$ The

\footnotetext{
1 Jehle/Wade Coping with Overloaded Criminal Justice Systems, Springer Heidelberg 2006.

J.-M. Jehle $(\bowtie)$

Department of Criminology, Institute for Criminal Law and Justice at the Law Faculty of the University of Göttingen, Platz der Göttinger Sieben 6, 37073 Göttingen, Germany e-mail: abtkrim@gwdg.de

M. Wade

Max-Planck-Institute for Foreign and International Criminal Law, Günterstalstr. 73,

79100 Freiburg i.B., Germany

e-mail:m.wade@mpicc.de

B. Elsner

Department of Criminology, Institute for Criminal Law and Justice

at the Law Faculty of the University of Göttingen,

Platz der Göttinger Sieben 6, 37073 Göttingen, Germany

e-mail: beatrix.elsner@jur.uni-goettingen.de
} 
study examined prosecution services in different European countries aiming to understand their national role and function within the respective criminal justice system and thereby to highlight common features and important differences between European systems. The roots of our study lie in the project which created the European Sourcebook of Crime and Criminal Justice Statistics. In 1996 the Council of Europe commissioned a group of specialists to prepare a collection of criminal justice data for the whole of Europe; since then the European Sourcebook has been published in several editions. ${ }^{2}$ The production of the chapter on public prosecution highlighted a lack of comparable statistical and legal information. Thus the idea for this in-depth study was born. The research was carried out in two waves: The first wave included England and Wales, France, Germany, the Netherlands, Poland and Sweden. The second wave worked with methodical instruments refined on the basis of experience gained from the first wave and covered those countries once more and additionally included Croatia, Hungary, Spain, Switzerland and Turkey. The project partners are criminal justice system experts and experienced comparative researchers, e.g. through their membership of the European Sourcebook group and other international committees: They were and are from the very beginning Chris Lewis for England and Wales, Bruno Aubusson de Cavarlay for France, Paul Smit and Martine Blom (first wave only) for the Netherlands, Beata Grusczynska, Teodor Bulenda, Andrzej Kremplewski (all first wave only) and Piotr Sobota for Poland, Josef Zila for Sweden, the German project management and research team consisting of Beatrix Elsner, Jörg-Martin Jehle, Julia Peters and Marianne Wade and - joining the group for the second wave - Ksenija Turkovic for Croatia, Erika Roth for Hungary, Marcelo Aebi and Marc Balcells Magrans for Spain, Martin Killias and Gladys Gilleron for Switzerland and Hakan Hakeri for Turkey. Due to the commitment of all the partners to our joint venture, the research instruments could be developed and the outcome validated in intensive sessions and bilateral discussions. All results presented in this volume are the product of the joint efforts of the group as a whole.

\section{Aim and Approach}

The study aimed to comparatively analyse the functions performed by prosecution services across Europe - by means of legal comparison in combination with empirical data reflecting actual working practice and factual mechanisms. The basic assumption is of criminal justice systems as a complex with different stages through which cases are passed and - from stage to stage - increasingly led out of, before they reach the court stage. The powers of, above all, the prosecution services to deal with cases in alternative ways form the heart of this study.

From a criminological point of view the prosecution service is regarded as a part of the criminal justice system as a whole. A system under pressure to deal with high numbers of cases in which the prosecution level is increasingly becoming the decisive (de-) criminalisation stage. An organisational-sociological point of view is integral to this; investigating how the prosecution services manage to deal with the high number of cases and proceedings in terms of reducing their workload by means of simplified methods and proceedings.

\footnotetext{
${ }^{2}$ European Sourcebook of Crime Justice Statistics (3rd ed). WODC, The Hague; by M. Aebi, K. Aromaa, B. Aubusson de Carvalay, G. Barclay, B. Gruszcynska, H. v. Hofer, V. Hysi, J.-M. Jehle, M. Killias, P. Smit, C. Tavares.
} 
Looking at the numbers of offences and suspects recorded one can observe that for decades an enormous rise in crime has taken place in West Europe, even if in some countries the crime rates have stabilised or are slightly declining in recent years. Increasing crime figures were also to be seen in Central and Eastern European countries for the last 17 years. It is obvious that the prosecution services and criminal courts cannot deal with their increased load unless staff numbers rise or the working mechanisms are changed.

In principle there are three possible ways of dealing with the increased number of criminal proceedings:

1. In accordance with the principle of legality all cases are prosecuted by the prosecution service and brought to charge in front of a criminal court where a judge deals with all cases in an oral hearing. For this scenario prosecution service and court personnel will have to be considerably increased. In a time of restricted resources this option has not proved popular.

2. Decriminalisation of substantive law: In this case the threat of a criminal sanction is removed for less serious breaches of the law. Either minor offences, especially traffic offences, are defined as "administrative" offences and a reaction ensues by administrative proceedings and fines. Alternatively or in addition minor offences in the "classic" field are decriminalised. This path does not appear to be politically viable; if at all, the current trend tends to favour increased criminalisation.

3. Discretion used by the police or prosecution service and simplified criminal procedure rules. The flood of criminal proceedings is mastered by procedural short cuts and simplifications. In this case the prosecution service often plays the central role and becomes the "judge before the judge". This option is the most frequently used.

With the choice of this third option, prosecution services become increasingly important within and play a vital role in European criminal justice systems as they are given more responsibility to decide how to deal with suspected criminals.

In order to understand the different national criminal justice systems and to establish a basis for comparison it is necessary not only to consider the prosecution service level, but to regard the criminal justice system as a complex and to evaluate the role and competence of the prosecution service within the system as a whole. In this way, one can observe the various decriminalisation and de-penalisation options being taken and the possibilities of discretionary decisions (case disposal) at police and prosecution service level. If a large proportion of cases is decriminalised, subject to a final decision by the police or dealt with outside of the criminal justice system, the prosecution service can concentrate on more serious offences and thus requires less discretionary powers. If - on the other hand - the police hand all offences on to the prosecution service, the criminal justice system will have to create "vents" at the prosecution level and allow for considerable discretion if the courts are not to receive all cases.

Thus the study deals with processes which are increasingly becoming the central, decision-making mechanisms of the evolving justice system, with far-reaching consequences for society and the fundamental principles of states bound by the rule of law.

\section{Design and Methods of the Study}

The study aimed for an international comparison of the prosecution service functions and its functional equivalents embedded in the respective systems of criminal justice as a whole. 
It had to evaluate the legal framework as well as factual handling within them. Therefore we had to develop a complex data collection instrument which allows the identification of similarities as well as the respective national peculiarities.

These tasks geared towards a study of national systems and an international comparison required a network of experts with representatives from each country to be formed, the creation of a working structure which provided for continuous electronic contact and an exchange of thoughts partly in bi-lateral meetings, partly in conferences involving all network members.

The following steps were necessary in order to provide for a comparative basis:

1. a common catalogue of questions to be studied

2. suitable common criteria, categories and instruments to collect statistical and informational data which display national peculiarities whilst providing a basis for comparative conclusions.

The agreement upon common categories and criteria is decisive for a fruitful comparison, at the same time, however, a very complex and difficult task. If one chooses English as the working language, as we did, difficulties arise on two levels: when describing national systems English legal language can often not provide a technical term for exact translation because certain legal concepts known in most of the continental European systems do not exist - at least not in the same form - in the English one. When compared internationally a specific institution within the legal systems studied is referred to by the same English term, but frequently has a (slightly) different meaning in the national context. We therefore had to search intensely for adequate categories, in order to find precise definitions and to elaborate the meaning of terms used. Nevertheless, in many cases, remarks and footnotes explaining deviations are necessary.

The categories and criteria developed together with the partners were incorporated in a questionnaire which was designed to comprehensively capture the legal and factual conditions.

The data collected related mainly to the following complexes:

- legal regulation of procedures, competences and decisions focally at the prosecutorial level but also in relation to police and courts

- organisational prosecution structures including the police and court levels

- statistical information concerning the personnel and material capacities, the procedures, procedural mechanisms and, in particular, the case-ending decisions at the prosecution level

- the decisive question as to how criminal justice system input is determined or rather which offences or offenders are dealt with outside of it as a consequence of decriminalisation.

\section{Questionnaire Relating to the National Level}

The original and follow-up questionnaire was divided into the following 13 sections $^{3}$ :
I. Offence Definition
II. Investigative Stage

\footnotetext{
${ }^{3}$ The content of the questionnaire and the completed questionnaires are available online under www. kriminologie.uni-goettingen.de/pps.
} 
III. Control by the Prosecution Service in the Investigative Stage

IV. Police Decisions

V. Unknown Offenders and Police Output

VI. Prosecution Stage: Input

VII. Prosecution Decision-making

VIII. Court Stage

IX. Prosecution Service's Legal Role

X. Control of the Prosecution Service and Individual Public Prosecutor (PP) Decisions

XI. Juveniles

XII. Victims

XIII. Basic Principles

Each section contained a number of questions aimed at identifying legal provisions for or information as to guidelines and other regulations of practice as well as any formal or informal provisions for working practice relevant to exploring the study's subject matter. The questionnaire started as a word document, but was converted into and augmented in a more stable format and sent as an electronic instrument to be filled in by computer. It was, for the most part, a structured questionnaire requiring the partners to tick one of a range of standardised answers provided. The abbreviated version followed the same pattern. There was always room to provide further comments and/or explanations. The initial round requested statistical information for 1993-2002, the follow-up study for 1994-2004. Partners were asked to trace any legislative and policy changes during this period. Much of the detailed statistical information requested was, however, not available in any of the jurisdictions studied. After the initial data collection phase was completed, the questionnaires were reviewed by the project management team. Where necessary, requests for clarification or additional information were made. For the rest of the project period bi-lateral discussions and meetings took place to ensure high quality, comparable data was attained.

The network meetings were also used to agree how to complement the information provided in the questionnaire in order to represent each national system in itself accurately. Some countries are adequately represented by the first stage country reports and an update in this thematic issue, with certain important specifics being explored in the thematic papers which follow. New partner countries completed reports in accordance to the original common structure to provide an overview of all the systems concerned as well as providing an opportunity to trace individual developments and features which the partners did not feel adequately highlighted in the common, standardised questionnaire.

\section{Comparison at International Level}

By creating common questions and categories for the questionnaire exploring the national level the basis for comparative analysis was achieved. The answers gathered by the national questionnaires were transferred to synoptical comparative tables for an interpretative evaluation drawing the essence of rules and practice in a certain field together.

Our analysis focuses centrally on the following issues:

- Which institution has effective control over the investigative stage?

- How and by what means are rising case-loads being dealt with by criminal justice systems complaining of a shortage of resources (is the principle of opportunity/the use of discretion becoming wide-spread in continental Europe)? 
- How far are differences between the common-law, Western and Eastern European criminal justice systems still in place, are there convergent trends?

- What case-ending function is played by the prosecution services and what is left to the courts?

- Issues relating to juveniles and victims are also explored.

In this way a comprehensive overview of how criminal justice systems work and what functions the various agencies, in particular the prosecution service, play within them should be achieved. Some of the comparative evaluation tables developed are used in the articles of this volume.

Another form of comparative synopsis is also used. We chose case examples ranging from administrative or minor (criminal) offences to increasingly serious offences and offenders. In this way how the criminal justice systems studied handle specific cases and whether they do so in a similar or different way can be demonstrated and compared.

\section{The National Criminal Justice Systems Studied}

The countries studied provide a fairly representative picture of the prosecution services in Europe $^{4}$. Large, small, eastern and western as well as the different prosecution service types were selected:

England (also covering Wales) provides an insight into a common law system which has only recently introduced a prosecution service and which itself is fairly stringently required to bring a large number of cases to court. Within that system the police, however, have broad discretion to deal with cases themselves, meaning a lower input to the prosecutorial level than in other countries.

France not only provides an opportunity to study the oldest prosecution service in Europe, but is exemplary for Romanic legal cultures, distinctively featuring not only a prosecution service, but also including a Jugé d'Instruction (Examining Magistrate).

The Netherlands provide an excellent example of a smaller western European country which is the most advanced in terms of dealing with cases informally, that is without a court hearing. The prosecution service there can be regarded as the "judge before the judge", due to its role in ending cases.

Sweden is included as representative of the Scandinavian legal culture which differs from the rest of Europe in several ways in particular in relation to the police role.

Poland provides an example of the eastern European legal culture, with a tradition of binding its prosecution services strictly to the principle of legality and a far-reaching decriminalisation of less serious offences.

Germany has a legal culture known for a traditional binding to the principle of legality and of mandatory prosecution which has, however, allowed increasing breaches of these during the past decades so that the legislative ideal type is now the exception in reality.

For the second wave new study countries were included: Croatia, Hungary, Spain, Switzerland and Turkey. These countries were selected because it was felt to be essential to reflect developments in East and Central Europe and in countries with a Romanic tradition more widely as well as to gather information on EU candidate countries and partner states.

\footnotetext{
${ }^{4}$ See also Jehle/Wade 2006 for the English and Welsh, French, German, Dutch, Polish and Swedish country reports.
} 


\section{The Study and its Central Issues}

In our study the criminal justice system is seen as a unit in which various (de-) criminalisation and (de-)penalisation options are provided for and different forms of discretion at police and prosecution service level take place. Therefore it is not easy to isolate certain levels and specific issues and to deal with the results in separate chapters. The same is true for the authorship. All results presented in this volume are the product of the joint efforts of the research group as a whole. Nevertheless we decided to separate different papers which certain authors are responsible for.

The article on "Paths to Control and Sanction Behaviour Necessitating a State Reaction" tries to establish a basis for the overall approach describing the different offence concepts and the different treatment of criminal cases within the criminal justice system. The paper on "The Criminal Justice Approach: Case Examples" has a similar function: to draw an overall picture by using case examples for the description of the variety of criminal justice system reactions. The article on "The Prosecution Role where Courts Decide Cases" refers to the ideal type of criminal proceedings, that is main proceedings with oral hearings, but focuses on the special function of PPS. The paper on "Negotiated Case-Ending Settlements: Ways of Speeding up the [Court] Process" deals with a topic increasingly becoming important in recent legal developments with some risks for the principles of equality and justice. Under the heading of "The Public Prosecutor as Key-Player: Prosecutorial CaseEnding Decisions" the core of the study is concerned: the decisive role of the public prosecutor regarding diversion, discretion and sanctioning within the criminal justice system. This central function is reflected in the article: "Tinker, Tailor, Policy-maker... The Wider Context of Prosecution Service Work"; it describes the legal status and competencies of PPS within criminal justice systems. The papers on "Police Case-Ending Possibilities within Criminal Investigations" and "The Police Prosecution Service Relationship within Criminal Investigations" analyse the complex relationship of PPS and police with tendencies to police's independence in investigations and the police's competence to sanction autonomously or by PPS's delegation. Only some of the countries studied are covered by the article on "The Examining Magistrate's Function and Involvement in Investigative Matters". The next paper shows the huge differences in "Dealing with Juvenile Offenders in the Criminal Justice System", but there is a common trend to divert juveniles from criminal proceedings and sanctions. Last but not least under the heading "Well-informed? Well represented? Well nigh Powerless? Victims and Prosecutorial Decision-making" the power of victims to influence the start, the ongoing and outcome of criminal proceedings is described. Subject of the further articles are national reports on the prosecution service function within the criminal justice system of Croatia, Hungary, Spain, Switzerland and Turkey.

Altogether the different chapters contribute to the aim of the study to provide for a comparative and complex overall picture of prosecution and diversion within the criminal justice systems in Europe. 